\title{
Formation and preservation of lacustrine enriched organic matter linked to volcanic
}

\section{ash?}

\author{
ZHIJUN JiN ${ }^{123}$, QUANYOU LiU ${ }^{12}$, XiNPING LIANG ${ }^{123}$, PENG \\ $\mathrm{LI}^{12}$ \\ ${ }^{1}$ State Key Laboratory of Shale Oil and Gas Enrichment \\ Mechanisms and Effective Development, Beijing, 100083; \\ ${ }^{2}$ Petroleum Exploration and Production Research Institute of \\ SINOPEC, Beijing, 100083; \\ ${ }^{3}$ School of Earth and Space Sciences, Peking University \\ jinzj.syky@sinopec.com
}

With the successful exploration and development of shale oil and gas in the Bakken and Eagle Ford Formations in North America, and Wufeng-Longmaxi Formation in China, the formation of organic-rich shales has drawn great attention. These black organic-rich shales are often accompanied by multiple layers of volcanic ash, but how these volcanic ash affect the formation and preservation of organic matter is still controversial. By analysis of volcanic ash in organic rich shale and microbial generation simulation experiments, this paper clarifies the role of volcanic activity in the formation of organic matter, and the reveals impact mechanism of deep fluid on the evolution of surface circles.

The Triassic Chang-7 Member shale in the Ordos Basin shows that the content of trace elements in the volcanic ash is higher than that in ordinary shales, and the content of nutrients is lower than the shale, while the high TOC of shale at the upper volcanic ash indicated that the nutrients carried by the volcanic ash would have migrated into shales, which had promoted the germination of microorganisms and improved paleoproductivity. The growth and cultivation simulation experiments of different hydrocarbon-forming organisms shows that an appropriate amount of volcanic ash carries nutrients and catalytic elements, which promoted biological prosperity and increased primary productivity, is conductive to form organic matter; excessive volcanic ash carries elements, which were toxic and inhibit the growth of organisms, is harmful to form organic matter.

The relationship between bacterial sulfate reduction index (SRI) and TOC indicates that the volcano-provided additional sulfate triggered BRS and generated a large amount of $\mathrm{H}_{2} \mathrm{~S}$. The high $\mathrm{H}_{2} \mathrm{~S}$ concentation enhanced the reducibility of the water body, and promoted the formation of sulfurized environment in water. The sulfurized water body is conducive to the preservation of organic matter. The statistics of the Chang-7 Member strawberry-shaped pyrite particle sizes in the shales at the upper and lower tuff are significantly smaller and more uniformly distributed than the area far from the tuff, indicating a more reduced water environment.

Keywords: volcanic ash, paleoproductivity, sulfide environment, lacustrine enriched organic matter 